\title{
Mandates of maternity at a science museum, from should to must
}

\author{
David Haldane Lee \\ NYC College of Technology, New York, USA
}

\begin{abstract}
A pregnancy exhibit at a science museum is an opportunity to research how medical advice is communicated and interpreted. This paper is about the Beginning of Life area of an exhibition called The Amazing You at the Tampa Museum of Science and Industry, where exhibits are prescriptive as well as descriptive. Expectant women are urged to deliver full-term, normal birthweight babies, by behaving according to prescribed medical norms. This study provides ethnographic descriptions of the exhibits, as well as insights from museum visitors who were interviewed. The exhibits, which emphasize fetal rights and maternal duties, are interpreted and critiqued by women visitors. As the exhibits climb towards greater realism (from euphemistic computer graphics to actual fetal specimens) visitors encounter assertions of fact that precede sometimes tacit directives to undergo a medicalized pregnancy. Exhibits are viewed from the perspective of speech act theory, presenting a new approach to health communication research. I argue that this science center exhibit tells people what to do, in addition to passing on information.
\end{abstract}

\section{Introduction}

The Amazing You (TAY) is a permanent exhibition at the Tampa Museum of Science and Industry (MOSI) that takes visitors through each stage of life, from conception to death. It contains 400 different health exhibits, each sponsored by Florida medical practices, device manufacturers, health insurance companies and government agencies. These sponsors sometimes influenced the content of the exhibits. For example, an ophthalmology practice provided videos of eye surgery, and a prosthetics manufacturer provided artificial limbs and organs. At the Beginning of Life (BOL) area of TAY, the topic is women as carriers and caretakers of fetuses. These 7 exhibits,

Correspondence: David H. Lee, NYC College of Technology, Department of Humanities, 300 Jay Street, Room A630, Brooklyn, NY, 11201.

Tel.: +1.813.313.6888.

E-mail: dlee@citytech.cuny.edu

Key words: maternal health, science museums, framing, positioning, speech acts.

Conflict of interest: the author declares no potential conflict of interest.

Received for publication: 13 May 2017.

Revision received: 28 July 2017.

Accepted for publication: 3 August 2017

This work is licensed under a Creative Commons Attribution NonCommercial 4.0 License (CC BY-NC 4.0).

CCopyright D.H. Lee, 2017

Licensee PAGEPress, Italy

Qualitative Research in Medicine \& Healthcare 2017; 1:93-102

doi:10.4081/qrmh.2017.6791 placed at the start of the exhibition have a strong prescriptive, even moralistic underpinning, because they insist on healthy choices made by mothers during gestation. I am interested in the ways that motherhood as a subject position $^{1-4}$ is constituted by this multimedia health campaign. In the ethnographic descriptions included in this paper I argue that the exhibits encourage women visitors to identify themselves as candidates for a medicalized pregnancy, and visitor responses show how they interpret and resist these mandates. This project is at the intersection of health communication and science center studies. It is derived from a larger, doctoral study of how health instructions are communicated to science museum visitors. The year this study was conducted, 73 million people visited science museums, ${ }^{5}$ and health exhibits are a common feature of these museums, yet there is not much health communication scholarship about them. While science center studies appear in a major communication journal, Public Understanding of Science, ${ }^{6-9}$ they are not specifically about health exhibits intended to change behaviors.

The key argument of this paper is that health exhibits issue directives in addition to informing visitors, an argument presented through a case study of the pregnancy exhibits at TAY. This research contributes to the literature by focusing on a kind of speech act, the directive, encompassing requests, suggestions and commands. ${ }^{10}$ Directives can be contrasted with assertives (or informational, descriptive statements) because rather than just describing, they seek to affect change in the addressee. In order to hide the explicit exercise of medical authority, medical directives can be embedded within statements of fact. For example, the message Quitting smoking now reduces serious risks to your health is a factual assertion, syntactically, but functions pragmatically as an indirect directive $\mathrm{e}^{11}$ to quit smoking. Characterizing messages as directives helps surface power differentials in medical discourse, be- 
cause the issuer of a directive presupposes their own authority and the obedience of the addressee. This is a power dynamic that is not addressed in most health communication research which privileges information-transfer. Looking at analogous developments in health education and museum studies provides an entry-point for investigating understudied health exhibits such as TAY, as well as the limitations of viewing communication exclusively as the transmission of facts.

\section{Health education, science centers, and behavior change}

Information-transfer approaches to health education are based on notions of passive individuals acquiring facts. ${ }^{12-14}$ The limited effectiveness of health campaigns based on information-transfer prompted more focus on changing behaviors in health promotion efforts, beginning in the 1980s. ${ }^{15}$ The shift from health education to health promotion $^{14,16,17}$ can be characterized as a rejection of education for education's sake. Instead of simply describing anatomical processes, individuals are instructed to prevent disease by eating better, exercising, losing weight, reducing stress and quitting bad habits like smoking. Given its preventative focus, health promotion messages have a wider audience beyond people with medical problems. They also address presymptomatic persons deemed at-risk because of lifestyle factors predicting disease. Because health promotion is also multisectorial ${ }^{14}$ it reaches beyond medical settings and into workplaces, schools and other public spaces such as science museums.

In ways analogous to health promotion, HooperGreenhill ${ }^{18}$ sees museums moving away from the information-transfer model and towards a conception of visitors as active participants. Similarly, Leinhardt and Knutson ${ }^{19}$ reject the osmotic perspective of museum learning, where people learn simply by being in the presence of important objects. Instead, they see museum learning as a participatory and interactive process. ${ }^{19}$ Traditionally, the purpose of health exhibitions is to inform, ${ }^{20}$ but during our interviews, MOSI executives rejected the strictly informative approach, describing TAY as a kind of public health intervention. Unlike human anatomy exhibitions presented according to a systems framework (i.e. skeletal, circulatory, etc.), TAY confronts visitors with action steps at each life stage, urging behavior changes. The exhibition is unique because it straddles these shifts from health education to health promotion, and from passive to active museum audiences.

\section{Materials and Methods}

This qualitative, exploratory study uses ethnographic observation and description, ${ }^{21}$ ethnographic interviewing, ${ }^{22,23}$ and multimodal methods ${ }^{24}$ suggested for the interpretation of multimedia. Upon IRB approval in the summer of 2012, data collection began by making reference videos of each exhibit, shot from the visitor perspective. I met 3 MOSI executives in the fall for unstructured interviews, and that winter I collected 72 one-page exit surveys from visitors. The survey posed open-ended, undirected questions, including What brought you to MOSI today?, What do you think about TAY? and Anything you liked in particular? that elicited responses other than yes/no. The last field in the survey invited the visitor to be interviewed in exchange for tickets to MOSI's IMAX Theater. 22 visitors were interviewed for about 15 to 40 minutes each. After obtaining informed consent I tried to ask undirected questions similar to those on the survey that allowed informants to steer the topic of conversation. I spoke to volunteers, solo visitors, groups of friends, couples and single or coupled parents. The convenience sample of mostly American visitors provided diverse responses in terms of age, groupings (dyad/triad), occupation, gender and ethnicity.

Interviews were transcribed using Dragon Naturally Speaking voice recognition software. Various descriptive terms and phrases appearing on the transcripts that my informants used to describe BOL were color-coded. I wrote descriptions of each video, a transduction ${ }^{25}$ of televisual data into descriptive text, and these fieldnotes were then coded using the same descriptive language highlighted in the transcripts. The approach was inductive, in that I did not start out with a testable hypothesis or theoretical orientation. It was inspired by grounded theory ${ }^{26-29}$ in that a theoretical explanation emerged during the process of data collection and analysis, rather than having been decided on beforehand. Classic concepts from pragmatics and sociolinguistics helped explain emerging themes.

\section{Theories of frames and speech acts}

As noted, MOSI executives stated that they set out to create a different kind of human body exhibition that they framed in interventionist terms. This helped me formulate research questions about museum exhibits that, in addition to passing on information, try to get the visitor to do something. I noticed that some exhibit titles contained commands, worded in the imperative mood (for example, "Stay Active", "You Be The Doctor", "Live Forever", "Do This, Not That" and "Use It Or Lose It"). Exhibits presented factual information, but apparently as a warrant for a directive, and there were also directives performing double-duty as assertions of fact. Codes from the transcripts and fieldnotes variously identified exhibits in sequences of descriptive and prescriptive messages. The museum communication systems literature helped identify audio, visual and tactile channels; ${ }^{30}$ components such as the exhibitor, exhibition and visitor ${ }^{31}$ and the joint meaning-making process of designers and visitors. ${ }^{32}$ But each of these models failed to address the content of messages as either descriptive or prescriptive. Seeking substantive theories to explain this distinction, I began to consider exhibits as 
made up of speech acts, which presupposes that they need not be vocal and verbal utterances. For example, hailing a cab is a non-verbal directive. The Searle taxonomy of speech acts ${ }^{10}$ provides a distinction between descriptive (assertive) and prescriptive (directive) messages. His concept of indirect directives ${ }^{11}$ describes commands or suggestions phrased otherwise, as an assertion, for example. Illocutionary force ${ }^{33}$ refers to the intended strength of a speech act, as indicated by the difference between should and $m u s t$, for example.

The notion of "act sequence" 34 describes speech acts that are linked together, such as an assertion that precedes a command. ${ }^{35-38}$ I was especially interested in the ways that assertions of fact were building blocks of a directive, because they provided the evidential warrant. ${ }^{39}$ Concepts of framing, ${ }^{40-43}$ broadly conceived, helped to characterize the selective presentations of facts, and what gets left out when complex health problems are depicted in multimedia. Framing also describes the concealment of illocutionary point and the modification of the illocutionary force of messages.

In the results section that follows, I present each exhibit from TAY's BOL area, including quotes from informants and theoretical insights to illustrate themes that emerged. I want to draw the reader's attention to how health issues are framed, and how directives are issued, sometimes tacitly. Visitors encounter a mix of assertions and directives about the duties of pregnancy and the rights of the fetus, while representational strategies go from euphemism towards graphic realism. Quotes show informants negotiating and resisting these rhetorical appeals, pointing out what is excluded when an exhibit frames an issue.

\section{Results}

\section{Introducing The Amazing You's Beginning Of Life area}

At the entrance to the TAY exhibition on MOSI's third floor there is a life-size plaster statue of a naked pregnant woman, under spotlights, signaling the start of a human lifespan. Her head bowed down, obscuring her face, she clutches her swollen abdomen with both hands, drawing attention to it. A text panel below reads:

YOU begin here. During our journey through life we gradually begin to understand ourselves. In each life phase there are new wonders to behold and new discoveries to make. YOU are amazing. Welcome to the AMAZING YOU!

The second-person, gender-neutral pronoun, YOU creates a situation of address. ${ }^{44} \mathrm{At}$ BOL you are a pregnant mother learning about how to deliver a healthy baby. Elsewhere in TAY, you are an adolescent learning how to resist peer pressure. Still later in the exhibition, you are an elderly person being told to complete crossword puzzles to postpone neurodegenerative diseases. MOSI executives stated that the exhibition is not about the body as some abstract object. In- stead it is about you, and in addition to imparting information it will enlist the visitor into a lifetime of biomedical interventions. The epicene pronoun you is being used deictically to hail various visitor demographics.

Some museum exhibitions take place in an open space in no particular order. By contrast, TAY is more rigidly sequential, because visitors are guided from one exhibit to the next by wall panels that form comb-like passages. Entering the low-lit, noisy exhibition, visitors first encounter BOL, which contains the following exhibits: "In My Womb", "Welcome To Our World", "Infant Roulette", "Early Arrival", "Pregnancy", "Biocontroversy" and "Fetal Remains".

\section{In My Womb}

Sponsored by the Morton Plant Hospital Bay Care Health System, the "In My Womb" video booth has a bench with seating for three. Each of these short videos provides narration summarizing a period of gestation between conception and birth, stressing how formative it is to the rest of human development. Computer animations represent the fertilization of an ovum, cell division, and organ development. Lupton ${ }^{14}$ notes the use of euphemism in health promotion discourse. These colorful digital images are the first example of euphemism being employed at TAY. Morgan ${ }^{45}$ argues that digital representations of embryos indicate ambivalence towards actual fetal specimens. After each video, the screen shows an image of what appears to be a woman's hand, with a fetus between her thumb and forefinger (Figure 1), as if holding the fate of her offspring in her hands. This image suggests the precarity of the fetus and the gravity of a mother's responsibility.

\section{WelcomeTo Our World}

The title of the next exhibit switches from a first-person singular pronoun (my) to a plural possessive (our). "Welcome to Our World: Video Footage of Actual Human Births" first shows 3D animations of a cervix dilating, a

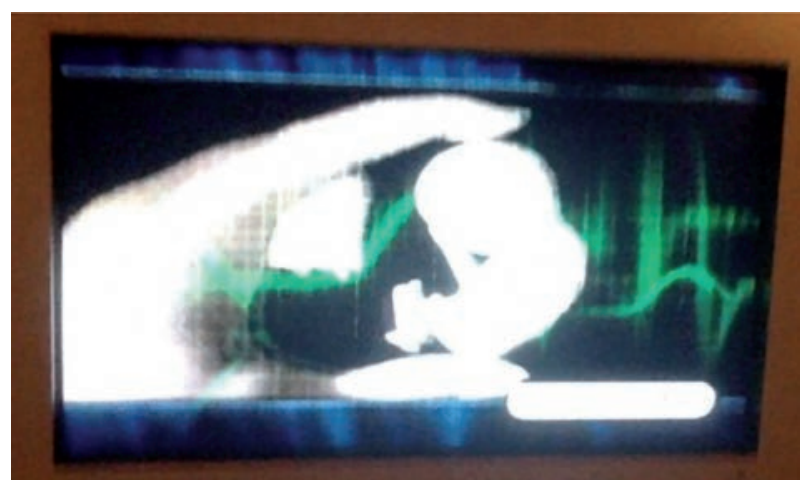

Figure 1. Feminine hand holding a fetus between thumb and forefinger ("In My Womb" exhibit). 
uterus contracting, and an in-vitro fetus rotating in the womb. Animations euphemistically show the birthing process, the crowning of the baby's head, and the delivery of the placenta. The videos that follow show graphic documentary footage of solo birth, the birth of twins, and a cesarean. They appear to take place in a hospital, indicated by hospital gowns and gloves worn by obstetrical professionals. One of my informants, a mother pseudonymously named Kay (who was visiting MOSI with her husband and two children) disliked the exclusive portrayal of hospital birth in these videos:

You walk in, and the first you see is the pregnancy and birth part...It assumes "I'm going to go to the hospital". There aren't any other alternatives considered. "I'm going to have an OB" and, really, that's not the way it really is in the world. They assume that everyone has the money to go through this whole hospital birth experience, and some people just choose not to. You know, I had her [daughter] at home, and everything was fine, and she turned out to be 10 pounds 6 oz., so she was really a big baby!

Based on her own experience, Kay notes that birth is being framed selectively in a medical setting. Her objections to the biomedical hegemony of obstetrics are shown in the following quote, where Kay describes the negative aspects of hospital childbirth:

If you go to the hospital, the first thing they do is hook you up to medical monitors, and they draw blood to test you for herpes and strep, and even before they get the results they start pumping you full of antibiotics... As soon as you walk in the door you are automatically put on a time limit, so if the labor isn't progressing according to their idea of the time limit they start with the medical interventions, which could be IV medication, intra-vaginally, or even caesarian. Most women end up on those medications, and then they tell the woman she needs to have an epidural... before you know it, you walk in the door and you are involved in all these medical interventions in processes that will occur naturally.

In this passage, Kay objects to the contrivance of a time frame and she portrays hospital birth as involving procedures beyond the mother's control, mandated even when medically unnecessary. Kay notes that women who decide on hospital birth are subjected to medical interventions, such as antibiotics and pain meds. The documentary footage of hospital birth is notable because it initiates a ramping up of realism as the exhibits move from away from computer generated abstractions. The staging of birth in a hospital setting appears to Kay as a tacit injunction to undergo a medicalized pregnancy.

\section{Infant Roulette}

At the next exhibit visitors spin a chrome steering wheel that shows post-natal injuries resulting from a mother's diet, overweight/obesity, or use of tobacco, al- cohol and drugs. For example, when the wheel stops on "Drugs" there is a photograph of an underweight baby in an incubator. A stanza of text explains that the consumption of illegal drugs during pregnancy can "cause miscarriage, premature labor, placental abruption, fetal death, birth defects and even maternal death". The text asserts that babies who are born addicted suffer "withdrawal symptoms, such as tremors, sleeplessness, muscle spasms, difficulties feeding, irritability, convulsions, diarrhea, fever, sleep abnormalties, and joint stiffness". The unsparing listing of symptoms, combined with photorealistic visuals, are an example of an indirect directive. ${ }^{11}$ It follows from the assertions of negative consequences that women should not use drugs while pregnant, but the directive is not stated. The implication of the roulette wheel is "don't gamble with your child's safety", reiterating the frame of maternal responsibility.

Paula, a health educator I interviewed (who was visiting MOSI with her mom) noted that Neonatal Abstinence Syndrome (NAS) was not mentioned, especially in the case of women who already gave birth:

.... and that's actually probably the target demographic that you have coming through here: women who have children and may be getting pregnant for a second time. Maybe they're on some sort of opiate from a surgical birth, or a follow-up complication, and now they're pregnant and their baby will be born addicted.

By drawing attention to what was omitted in "Infant Roulette", Paula suggests the possible health consequences when an exhibit leaves out important information. Over 20K U.S. infants a year are born with NAS, a fivefold increase since $2000,{ }^{46}$ corresponding to a national opiate prescription crisis. Paula also said that the representation of Fetal Alcohol Syndrome (FAS) at "Infant Roulette" was missing some details:

...When you talk about the FAS it is really now like a spectrum of disorders. It also doesn't really say anything - doesn't really specify that a glass of wine a day could be considered - [that] there's no amount of alcohol that's actually been proven safe.

Despite the playful frame provided by the roulette wheel, "Infant Roulette" is a serious informational exhibit describing the consequences of some risk behaviors. Implicit, but going without saying, is an injunction to avoid harming your fetus, although Paula implies that women need the right kind of information to carry out that injunction.

\section{Early Arrival}

Around the corner is an incubator with a realistic model of a little baby inside (Figure 2). Preterm babies are defined as being born any time before they reach 37 weeks old, and text explains that one in nine (or half a million) children in the U.S. are born premature each year. They struggle with breathing, digestion, hearing and vision, and may face long term learning and behavioral difficulties. Subheadings em- 
phasize the maternal role in preterm birth. "Mother's Medical Risk Factors" lists conditions, including high blood pressure, diabetes, and being over or under weight. "Mother's Lifestyle and Environmental Risk Factors" lists smoking, alcohol use, and illegal drug use (abuse of legal drugs is not mentioned). Other risk factors on the list suggest social determinants beyond a woman's control, including the lack of a social support system, working long hours, and stress. Another stanza of text, entitled "A Growing Problem?" notes that premature births increased 30\% since 1983 , but this may be partly an artifact of more stringent diagnostic criteria. The last line of text reads "Statistics clearly show that early and good prenatal care reduces your chances of premature birth". This sentence is a prototypical indirect directive, phrased in the indicative mood but suggesting an action to take.

While social determinants are acknowledged, "Early Arrival" frames the responsibility for premature birth mostly in terms of the mother's behaviors. Paula, who works as a smoking cessation specialist with expectant mothers, told me that some women prefer to have a smaller baby.

In certain populations, I mean, it's desirable. Smoking causes low birth weight babies, so they think of that as a bonus-like, 'Oh, the baby will weigh less. That's better for me'. They don't want to have to carry or have to push a heavier baby.

She described her clients as not being forthcoming about their tobacco use:

Everybody thinks they're different; everybody thinks they're especially unique and their actions are not going to be the norm. The exception to the rule. Nobody's honest with me, especially when you meet women who are pregnant and smoking; if they tell you they're smoking four cigarettes, they're smoking twenty.

Rather than rushing to the defense of pregnant mothers, Paula, above, portrays them as self-interested and duplici-

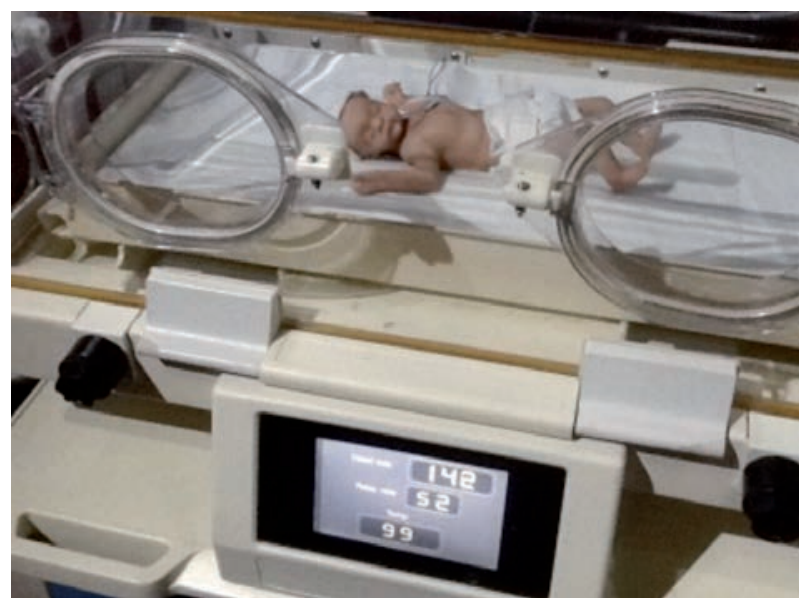

Figure 2. Realistic model of premie ("Early Arrival" exhibit). tous, as if agreeing with the victim-blaming frame of "Early arrival". While fact-checking the claims made in the exhibit, I found a WHO fact sheet that framed premature birth more broadly, listing as causal factors "multiple pregnancies, infections and chronic conditions...however, often no cause is identified". ${ }^{47}$ Other causal factors not mentioned in the either the exhibit or WHO fact sheet are environmental, such as air pollution, ${ }^{48,49}$ lead exposure,${ }^{50}$ and household chemicals. ${ }^{51}$ By selectively framing its etiology, "Early Arrival" makes moms the primary culprits for premature birth, while structural factors such as poverty, environment, and access to prenatal care are downplayed.

\section{Pregnancy}

Harré $^{2}$ describes positioning theory as the study of illocutionary force associated with shared assumptions about rights and duties. Positions (similar to roles but more fluid) are defined by rules that carry varying degrees of urgency, from the merest suggestion to the compulsory. At BOL, motherhood is a subject position with obligations, because women who conceive enter into a medically predefined course of action. A maternal deontology (meaning, duties and obligations) is emphasized where the mother is responsible for post-natal injury. While the eponymic you of TAY has so far been addressed to the mother, the next exhibit tries to address a broader swath of subject positions by way of pronoun disagreement.

The "Pregnancy" exhibit shows a cross section diagram of an expectant woman's torso, photos of swollen feet, and two taut, distended abdomens of women close to delivery. Text describes symptoms of pregnancy, including hormone imbalance, pain, constipation, hemorrhoids, increased frequency of urination and skin pigmentation. The last stanza of text contains an array of addressees, which appear bolded below to highlight typographical errors which arguably have an unintended rhetorical effect.

The changes of pregnancy can be uncomfortable. But if she is aware of the potential for pain and take appropriate steps to avoid it or relieve it when it occurs, you'll go through the nine months in relative comfort. Consulting with a health professional is the best way to find out what is best for the mother and baby.

This stanza issues a directive to gravid women (and others in her interpersonal orbit) to avoid and relieve pain while consulting with health providers. Notice the pronoun shifts from third-person singular (she) to secondperson personal (you'll), to definite articles (mother and baby), addressing the variety of persons who will view the exhibit. By switching identifiers mid-sentence, the "Pregnancy" exhibit may unintentionally be heralding other subject positions, such as the father, children, grandparents or others with a second-person relationship to the pregnant woman. The shifts in addressee invite others to consider pregnancy, helping prepare the visitor for the next exhibit, where they are asked to consider criminalizing neglectful mothers. 


\section{Bio-controversy}

"Bio-controversy" is a video booth located toward the end of BOL, tackling controversial issues, including irresponsible mothers. Pro and con arguments are made by actors in minute long videos. After each video, both actors ask, in unison, "What do you think?" letting visitors decide who won the debate. However, instead of balancing both sides of an issue, this exhibit contains hints to the viewer as to which is the preferred argument. Medical authority, played by a grey-haired male actor in a white coat, usually makes a stronger case. In the video, Drugs, Smoking And Drinking While Pregnant, a question appears onscreen: "Should a mother who smokes, drinks alcohol, or does illicit drugs while pregnant be liable for criminal charges?" Background pictures show a pregnant woman holding a cigarette and a beer bottle, and a woman behind bars. The grey-haired actor who (according to scripts provided to me by MOSI design staff) is portraying a "Medical Expert", says calmly:

The consumption of illicit drugs, alcohol and smoking puts chemicals into the pregnant mother's blood stream, which cross the placenta and can affect the fetus. Babies are more likely to be born prematurely, have complications, be drug addicted themselves, have mental retardation, have heart and face defects, and much more. Some states have successfully prosecuted the mother for child abuse.

The short argument above can be seen as a series of assertions preceding a directive to criminalize pregnant women, although it is never stated outright. In classical rhetoric, a practical syllogism has as its conclusion the performance of an action, following from a major and minor premise..$^{52}$ Accordingly, the medical expert's practical syllogism might be restated as follows: Abuse is illegal; this is abuse. The action step that follows is to support criminalization. The medical expert could plausibly deny he is endorsing criminalization, but is instead making mention of a possible policy response. With the action step unstated, but reasonably following from the premises, the audience is enlisted to come to the preferred conclusion.

The next half of the video shows a young actress portraying a "Female Rights Advocate" who provides a rebuttal:

A woman has the right to do what she wants to her body. It is not a crime to be pregnant, and it is not a crime to be an addict. So why should it be a crime to be a pregnant drug/smoking/alcohol addict? Making this a legal matter would make substance abuse mothers less likely to get pre-natal care, which puts the baby at far greater risk. She needs help, not punishment.

The stanza uttered by the female rights advocate can be also seen as a sequence of speech acts, in this case not all assertions. The first two assert the rights of women and the legality of pregnancy and addiction. These are followed by a rhetorical question, and the last two sentences are directives, because they take a stand and issue a policy recommendation: help pregnant women rather than punishing them. Neither interlocutor says that drugs and drinking during pregnancy is a good idea, but the female rights advocate asserts that criminalizing behaviors will result in women not getting needed medical help.

Viewers of the video are provided with some hints about which side of this controversy is preferable. For one, the woman carries the title of female rights advocate, suggesting that her position is political rather than dispassionately scientific. In fact, the move to criminalize expectant mothers has been characterized as ideologically motivated, and opposed by obstetricians and addiction specialists. ${ }^{53}$ Another clue undermining the credibility of the female rights advocate is the equivalence fallacy "It is not a crime to be pregnant, and it is not a crime to be an addict. So why should it be a crime to be a pregnant drug/smoking/alcohol addict?" For analogy, consider "Drinking is legal, driving is legal, so why should drinking and driving be illegal?" The visitor has been tacitly steered towards the medical expert's indirect directive to criminalize, given the logical fallacy of his opponent.

\section{Fetal Remains exhibit}

Outside the last exhibit there is a large photo of a fetus in vitro. Towards the entrance, a plaque announces that visitors are about to see a collection of fetal specimens on loan from the Human Development branch of the National Museum of Health and Medicine, a part of the Armed Forces Institute of Pathology of the Walter Reed Army Medical Center. Around a glass divider in a dimly lit area are 7 clear cylinders, illuminated by floodlights, each containing a fetus suspended in formalin. The collection includes a fetus at 6 weeks, 10 weeks, 11 weeks, 12 weeks, 13 weeks and the largest, a 27 weeks-old specimen. At the bottom of each cylinder there is a plaque explaining what is happening at each developmental stage. For example, "By 13 weeks the sex of the embryo can be identified."

Representational technologies at BOL have so far included computer graphics, documentary videos, plastic models and finally, the realism provided by human remains. As the climactic exhibit, this was the one that survey respondents and interview participants most wanted to talk about. They were concerned with the authenticity of the fetuses, where they came from, and the exhibit's appropriateness for children. The plastic premie baby from "Early Arrival" was perhaps realistic enough for visitors to doubt the authenticity of these fetal specimens.

Coleen, visiting with her 8-year-old son (who was exploring the nearby exhibits as I spoke with his mom), was surprised:

No way! I don't think it actually registered just now that they were really...real ones! [laughs] you know? That might have flipped him out if he knew. But I didn't mention it, he didn't read it, I just kind of glossed over it. He said "Oh yeah that's neat!" I said "all right!" I think in his mind, he is thinking they were 
models. It's fine. Doesn't bother me. If he had a question about it, I would just explain.

An educated young woman without kids who worked in marketing, Elizabeth was concerned about the origins of the fetal specimens. I noted that the plaque said they were on loan from Walter Reed, but she replied,

It just says that they are on loan, but they don't say if they are real or not. Like I know in the Bodies exhibit... the bodies were real, and it was very controversial about where the bodies came from. So I assume it was also controversial here, and especially since there are issues about pro-life and pro-choice. And you have people on different sides, obviously, and they may be confused or curious, and then maybe having to explain to their kids. Elizabeth is referring to the museum exhibition Bodies, which was shown at MOSI in 2005, featuring actual human remains, preserved by a process called plastination. The exhibitor, Premier Exhibitions, maintained that the corpses used in the exhibition were obtained legally in China, but details were scant, leading to a legal settlement with the NYS Attorney General in 2008. ${ }^{54}$ The comments of Elizabeth, above, situate the fetal remains exhibit in social and political context, which is left out when fetuses are used to represent sui generis developmental stages.

Another woman named Alexis, also wondered about their origins:

I think that they should have something clearly written out that says these were babies that were unable to develop any further and they weren't killed to provide this display. They aren't like a real live person at all, so that people, especially children, can understand. "How did they get in the jar, Mommy?" I assume that they were fetuses who were naturally aborted or miscarried and they were used for this purpose after their lives had ended.

According to MOSI staff, the Walter Reed Medical Center didn't provide details about the provenance of the specimens, only that they may be over one hundred years old. The initiative to collect and preserve fetal material is associated with the embryologist Franklin Paine Mall, director of the Carnegie Institution Department of Embryology, founded at John Hopkins Medical School in $1913,{ }^{45}$ who solicited human embryos from doctors whose patients had miscarried. According to Morgan ${ }^{45}$ the impulse to collect fetuses was in the interests of science, and can be viewed as defensible in historical context. The fetal remains may signify what Layne ${ }^{55}$ argues is a taboo topic for American parents: the memory or mention of pregnancy loss. These relics of early $20^{\text {th }}$ century scientific curiosity have been supplanted by neater, more palatable representation technologies such as computer graphics.

\section{Discussion}

Apart from some key studies ${ }^{56-58}$ the directive speech act has not been a primary focus of communication inquiry, let alone the subfield of health communication. A measure of successful public health interventions is the degree to which target audiences submit to and comply with prescribed regimens, and in order to comply they first need to be asked. While directives are abundant in public health messages that instruct and persuade, many health communication studies don't clearly distinguish reporting and ordering. No doubt, receiving and understanding the right information improves outcomes, but in this paper, I have suggested how assertions of fact can be used to justify a directive that follows. Researching the assertive-directive speech act sequence has the potential to enlarge the discussion about health messages, adding to a fuller understanding of what recipients are expected to do with the information they receive.

BOL doesn't just pass on information; it is full of shoulds and musts, both overt and implicit, for expectant mothers. Because choices made during pregnancy have such formative effects, mothers are framed as vessels for humanity, foregrounding their duties and the rights of the fetus. ${ }^{59}$ Concepts of educational scaffolding ${ }^{60,61}$ describe how support systems that help introduce new ideas and procedures can gradually be removed as learners progress. Arguably, BOL eases visitors into difficult topics through a progressive movement towards greater realism and urgency. As such, the exhibits are climax-ordered,${ }^{62}$ culminating in a macabre directive for expectant women to walk the straight and narrow and opt for a medicalized pregnancy.

This analysis shows a ramping up of illocutionary force, as exhibits become increasingly realistic and focused on prenatal dangers. "In My Womb" has computer animations focused on normal gestation, and "Welcome To Our World" begins with animations, then shows actual birth videos. "Early Arrival" presents a realistic 3D model of an underweight baby, and finally, actual aborted fetuses are shown.

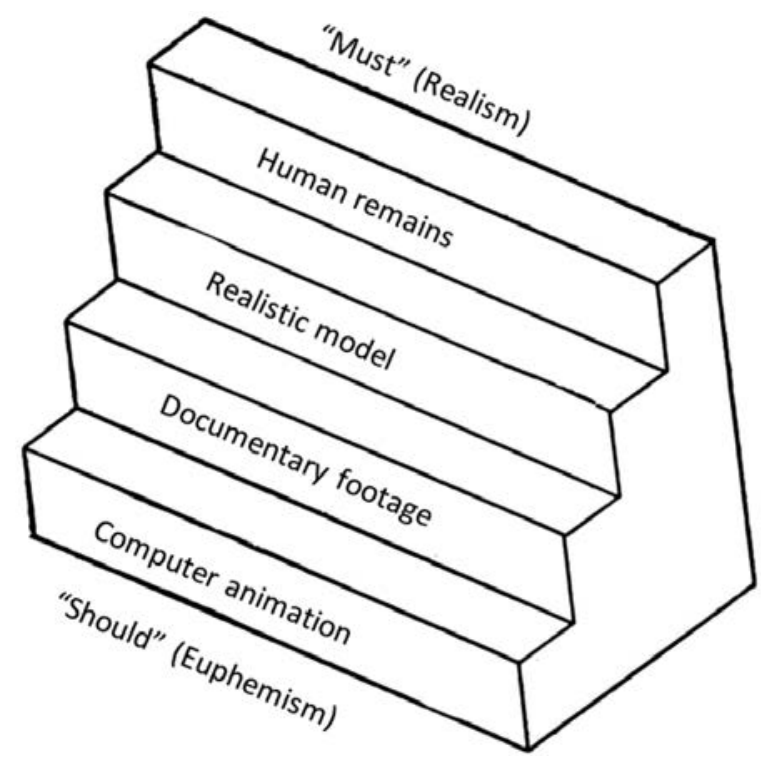

Figure 3. Representational staircase going from should to must as the exhibits get more realistic. 
Depictions climb a representational staircase (Figure 3) from euphemism to realism. The staircase diagram correlates representational mode and illocutionary force. That is, as depictions become more explicit, auxiliary verbs of necessity (must) supplant suggestions (should), heightening urgency for the visitor. This is a hypothesis of BOL as a multimodal argument using assertions to predicate moral mandates about maternal responsibilities, as evidenced by the exhibits and informant insights.

Paula noted what information was lost during a transduction of medical expertise into multimodal exhibits, and Kay noted the preferential portrayal of hospital birth, both drawing attention to framing. Coleen, Elizabeth and Alexis voiced a sense of shock about the fetal specimens and wondered about their authenticity and origins - their concerns phrased in vocabularies of "real" and "actual". The quotes show them seeking "footing" ${ }^{63}$ as frames become more realistic and subject positions shift. Positions are addressed throughout BOL using pronouns or definite articles. Unnamed, unparented, the fetuses efface subjecthood and establish in its place the grand third-person, singular-neuter pronoun, $i t$. Their manifest function is to represent developmental stages, but is their latent function a warning? Can the fetal remains be viewed as an indirect directive? Are women being told to place the selfhood of their child over their own, lest it be still born? An implicit object lesson about miscarriage, warning women about what can happen if they don't behave? In posing these questions, I'm speculating less about the intentions of MOSI and the exhibit designers, and more about a potential interpretation, although unarticulated by my informants in such terms.

What makes the present study unique is the consideration of speech acts other than assertions, which helps surface assumptions about behavior change. The results show how the illocutionary force of a directive can be ambiguated by stating it indirectly, in the form of an assertion. Health communication studies note the problem of reactance to controlling language ${ }^{64-66}$ which helps explain motives behind the strategic attenuation of illocutionary force. Questions for further research are related to the attenuation and amplification of risk, ${ }^{67-69}$ except approached from the perspective of speech acts. Namely, how can representational means (from euphemism to realism) alter the illocutionary force of multimodal messages? Does explicit realism necessarily correspond with stronger, more forceful health directives? While modalities in language express possibility and necessity to varying degrees, can a defensible analogy be made with multimodal health messages?

\section{Limitations}

Although presented under traditional subheadings, the reader will note discussion and analysis throughout, intended to show how existing theory was consulted in concert with data analysis. This essay is not typical of visitor studies that measure learning outcomes. Informants were not asked directed questions, so they spoke only about exhibits that interested or concerned them. Notice men didn't comment. A follow-up study will employ a more directed survey instrument to investigate the hypothesis that modes of representation correspond to perceived illocutionary force. There is also a reflexive dimension, unexplored here, regarding how my own subject position (male, childless, middle-aged, white, etc.) influenced the research process. Despite these limitations, I believe a fresh approach to the under-researched topic of medical directives at science museums is presented here. Showing how multimodal messages link together reports and commands helps foreground what the messenger wants the recipient to do with the information they get, clarifying the intent of public health interventions. This offers health communication and museum practitioners an opportunity for clearer communication and more explicit agendas.

\section{Conclusions}

This study presents four different findings about BOL that can be itemized as follows: i) The selective framing of pregnancy, emphasizing women's individual behaviors over structural determinants. ii) Techniques of subjectifying women as candidates for a medicalized pregnancy, such as euphemism, pronouns, logical flaws and indirect directives. iii) Foregrounding the rights and personhood of the fetus, provoking questions about the authenticity and origins of the fetal remains. iv) A ramping up of realism corresponding with increased urgency or illocutionary force.

BOL hails women into a deontology of medicalized pregnancy, contrasting normal pregnancy with pathological scenarios of premature birth and miscarriage, which serve as warnings. The dominant frame of BOL is that women are responsible for post-natal harm resulting from their behaviors, while the structural determinants of health are underexplored. While empowerment is unobjectionable, there is a risk of victim-blaming when the mother's agency is overstated. Women's responses show strategies for interpreting and resisting biomedical onuses.

This paper views science center exhibits as speech acts in sequence, with the directive sometimes unstated, but following assertions as a matter of course. The implication for further research is that speech acts need to be considered multi-modally (not only in their paradigmatic verbal form), and in sequence instead of as stand-alone units of analysis. This approach can help further health communication beyond a narrow focus on information transmission.

\section{References}

1. Davies B, Harré R. Positioning: the discursive production of selves. J Theory Soc Behav 1990;20:20.

2. Harré R. Positioning theory. Self-Care Dependent-Care Nursing 2008;16:28-32.

3. Kerr A, Cunningham-Burley S, Tutton R. Shifting subject 
positions: experts and lay people in public dialogue. Soc Stud Sci 2007:37:385-411.

4. Braun K, Schultz S. “. . a certain amount of engineering involved": constructing the public in participatory governance arrangements. Public Underst Sci 2010;19:403-19.

5. ATSC. 2011 Science center and museum statistics. 2014: Available from: http://www.astc.org/wp-content/uploads/ 2014/10/2011-Science-Center-Statistics.pdf.

6. Macdonald S, Silverstone R. Science on display: the representation of scientific controversy in museum exhibitions. Public Underst Sci 1992;1:68-87.

7. Henriksen EKF, Frøyland, M. The contribution of museums to scientific literacy: views from audience and museum professionals. Public Underst Sci 2000;9:393-415.

8. Bud R. Science, meaning and myth in the museum. Public Underst Sci 1995;4:1-16.

9. Yaneva AR, Rabesandratana TM, Greiner B. Staging scientific controversies: a gallery test on science museums' interactivity. Public Underst Sci 2009;18:79-90.

10. Searle JR. A classification of illocutionary acts. Lang Soc 1976;5:1-23.

11. Searle JR. Indirect speech acts. In: Cole P, Morgan JL, eds. Syntax and semantics, vol. 3: Speech acts. New York: Academic Press; 1975. pp 59-82.

12. Beattie A. Knowledge and control in health promotion: a test case for social policy and social theory. In: Gabe J, Calnan M, Bury M, eds. The sociology of the health service. London: Routledge; 1991. pp 162-202.

13. Weare K. The contribution of education to health promotion. In: Bunton R, Macdonald G, eds. Health promotion: disciplines, diversity and developments. 2nd ed. New York: Routledge; 1992. pp 102-25.

14. Lupton D. The imperative of health: public health and the regulated body. Thousand Oaks: Sage; 1995.

15. Nutbeam D. Health literacy as a public health goal: a challenge for contemporary health education and communication strategies into the 21 st century. Health Promot Int 2000;15:259-67.

16. Tulchinsky TH, Varavikova E, Bickford JD. The new public health. 3rd ed. Cambridge: Academic Press; 2014.

17. Petersen AR, Lupton D. The new public health: health and self in the age of risk. St. Leonards, NSW, Australia: Allen \& Unwin; 1996.

18. Hooper-Greenhill E. The educational role of the museum. 2nd ed. New York: Routledge; 1999.

19. Leinhardt G, Knutson K. Listening in on museum conversations. Walnut Creek: Altamira Press; 2004.

20. Danilov VJ. Science and technology centers. Cambridge: MIT Press; 1982.

21. Agar M. The professional stranger: an informal introduction to ethnography. New York: Academic Press; 1980.

22. Spradley JP. The ethnographic interview. New York: Holt, Rinehart and Winston; 1979.

23. Atkinson P. Handbook of ethnography. London: Sage; 2001.

24. Bezemer J, Jewitt C. Multimodal analysis: key issues (preprint version). In: Litosseliti L, ed. Research methods in linguistics. London: Continuum; 2010. pp 180-97.

25. Kress G. Multimodality: a social semiotic approach to contemporary communication. Abringdon, UK: Routledge; 2010.

26. Glaser BG, Strauss AL. The discovery of grounded theory: strategies for qualitative research. Chicago: Aldine Publishing Company; 1967.
27. Charmaz K. Constructing grounded theory. Thousand Oaks: Sage; 2006.

28. Corbin JM, Strauss AL. Basics of qualitative research: techniques and procedures for developing grounded theory. 3rd ed. Los Angeles: Sage; 2008.

29. Lindlof TR, Taylor BC. Qualitative communication research methods. 3rd ed. Thousand Oaks: Sage; 2011.

30. De Borhegyi S. Visual communication in the science museum. Curator 1963;6:45-57.

31. Cameron D. A viewpoint: the museum as a communications system and implications for museum education. Curator 1968;11:33-40.

32. Hooper-Greenhill E. A new communication model for museums. Curator 1991;6:45-57.

33. Searle JR. Speech acts: an essay in the philosophy of language. London: Cambridge University Press; 1969.

34. Hymes DH. Foundations in sociolinguistics: an ethnographic approach. Philadelphia: University of Pennsylvania Press; 1974.

35. Frentz TS, Farrell TB. Language-action: a paradigm for communication. Q J Speech 1976; 62:333-49.

36. Van Dijk TA. Pragmatic connectives. J Prag 1979;3:447-56.

37. Wunderlich D. Methodological remarks on speech act theory. In: Searle JR, Kiefer F, Bierwisch M, eds. Speech Act Theory and Pragmatics. Amsterdam: Springer; 1980. pp 291-312.

38. Cooren F. The contribution of speech act theory to the analysis of conversation. In: Fitch KL, Sanders RE, eds. The handbook of language and social interaction. New York: Psychology Press; 2005. pp 21-40.

39. Toulmin S. The uses of argument. Cambridge: Cambridge University Press; 1958.

40. Goffman E. Frame analysis: an essay on the organization of experience. Cambridge, MA: Harvard University Press; 1974.

41. Tannen D. Framing in discourse. New York: Oxford University Press; 1993.

42. Hom AG, Plaza RM, Palmén R. The framing of risk and implications for policy and governance: the case of emf. Public Underst Sci 2011; 20:319-33.

43. Steier F, Jorgenson J. Ethics and aesthetics of observing frames. Cybern Human Knowing 2003;10,124-36.

44. Benveniste E. Problems in general linguistics. Coral Gables: University of Miami Press; 1971.

45. Morgan LM. The rise and demise of a collection of human fetuses at mount holyoke college. Perspect Biol Med 2006;49:435-51.

46. NIDA. Dramatic increases in maternal opioid use and neonatal abstinence syndrome. Bethesda: National Institute of Health, National Institute on Drug Abuse; 2015; Available from: https://www.drugabuse.gov/related-topics/trends-statistics/infographics/dramatic-increases-in-maternal-opioiduse-neonatal-abstinence-syndrome.

47. WHO. Preterm birth fact sheet: World health organization. Regional office for europe. Geneva 2013. Available from: http:/www.who.int/mediacentre/factsheets/fs363/en/ index.html.

48. Stieb DM, Chen L, Eshoul M, et al. Ambient air pollution, birth weight and preterm birth: a systematic review and meta-analysis. Environ Res 2012;117:100-11.

49. Darrow LA, Klein M, Flanders WD, et al. Ambient air pollution and preterm birth: a time-series analysis. Epidemiology 2009;20:689-98.

50. Torres-Sanchez LE, Berkowitz G, Lopez-Carrillo L, et al. 
Intrauterine lead exposure and preterm birth. Environ Res 1999;81:297-301.

51. Fei C, McLaughlin JK, Tarone RE, et al. Fetal growth indicators and perfluorinated chemicals: a study in the danish national birth cohort. Am J Epidemiol 2008;168: 66-72.

52. Gottlieb P. The practical syllogism. In: Kraut R, ed. The blackwell guide to Aristotle's nicomachean ethics. Oxford, UK: Blackwell Publishing Ltd; 2006.

53. Eckholm E. Specialists join call for veto of drug bill. New York Times. 04/15/14.

54. Wilson M. 'Bodies' exhibitors admit corpse origins are murky. New York Times. 05/30/2008.

55. Layne LL. Motherhood lost: a feminist account of pregnancy loss in America. New York: Routledge; 2003.

56. Ehninger D. Towards a taxonomy of prescriptive discourse. In: White EE, ed. Rhetoric in transition: studies in the nature and uses of rhetoric. University Park, PA: Pennsylvania State University Press; 1980. pp 89-100.

57. Fitch KL. A cross cultural study of directive sequences and some implications for compliance gaining research. ComM 1994;61:185-209.

58. Labov W, Fanshel D. Therapeutic discourse: psychotherapy as conversation. New York, NY: Academic Press; 1977.

59. Oaks L. Smoking and pregnancy: the politics of fetal protection. New Brunswick: Rutgers University Press; 2001.
60. Pea R. The social and technological dimensions of scaffolding and related theoretical concepts for learning, education, and human activity. J Learn Sci 2004;13:423-51.

61. Puntambekar S, Hübscher R. Tools for scaffolding students in a complex learning environment: what have we gained and what have we missed? Educ Psychol 2005;40:1-12.

62. Hovland CI. The order of presentation in persuasion. New Haven, CT: Yale University Press; 1957.

63. Goffman E. Footing. Forms of talk. Philadelphia: University of Pennsylvania Press; 1981. pp 124-59.

64. Shen L. Antecedents to psychological reactance: the impact of threat, message frame, and choice. Health Commun 2014;30:975-85.

65. Richards AS, Banas JA, Magid Y. More on inoculating against reactance to persuasive health messages: the paradox of threat. Health Commun 2016:1-13.

66. Xu J. The impact of locus of control and controlling language on psychological reactance and ad effectiveness in health communication. Health Commun 2016:1-9.

67. Kasperson RE, Kasperson JX. The social amplification and attenuation of risk. Ann Am Acad Pol Soc Sci 1996;545:95-105.

68. Schütz H, Wiedemann PM. Framing effects on risk perception of nanotechnology. Public Underst Sci 2008;17:369-79.

69. Goodman JR, Goodman BP. Beneficial or biohazard? How the media frame biosolids. Public Underst Sci 2006;15:359-75. 